Journal of Engineering and Applied Sciences 14 (5): 1395-1400, 2019

ISSN: 1816-949X

(C) Medwell Journals, 2019

\title{
A Study on the Factors Affecting University-Industry Collaboration's Competence
}

\author{
${ }^{1}$ Gyeong-Min Nam and ${ }^{2}$ Dae-Geon Kim \\ ${ }^{1}$ Industry Cooperation Team, National Research Foundation of Korea, Busan, South Korea \\ ${ }^{2}$ Department of Architectural and Civil Engineering, Dong-seo University, Busan, South Korea
}

\begin{abstract}
With the advent of the 4th industrial revolution, interdisciplinary studies based on ICT have won global attention as a growth engine for the future. Also, society has been through changes in every aspect from education to employment in accordance with population decline and aging accelerated. Accordingly, to preemptively respond to these changes, universities and corporations began to innovate themselves through reciprocal cooperation. The purpose of this study is to identify the factors affecting university-industry collaboration performance and to carry implications for government policy by analyzing the effect of government driven program.
\end{abstract}

Key words: University industry collaboration, policy, entrepreneurship, government driven, LINC, population decline

\section{INTRODUCTION}

In 1990's with the advent of the knowledge society, the way to produce and consume knowledge has changed. Beforehand, knowledge was produced and delivered by only selected group of people, thus, it took a long time to change paradigms. In accordance with the increase of information accessibility and the development of ICT, however, most people can easily access to collective data and produce a variety of information through interaction. It has led the university to take on a role in socio-economic development in addition to teaching and research. As a result, the university has started to create added value through technology transfer and commercialization. This paradigm shift to academic capitalism was introduced in Korea with social changes such as the decline of the school-age population and deterioration in university's finance. Also, the government has been supporting the university-industry cooperation by policies since 1960 's.

These changes can be interpreted from the perspective of resource dependence theory. In response to the lack of resources and changes in external environments, universities have ties to governments with money and businesses with commercialized technologies and markets. Each relationship is for different purposes; the government will have power in its relationship with universities, mainly as possessing financial resources. Therefore, it exerts an influence to change the universities in the direction it wants. On the other hand in relation to businesses, universities have an equal level of relationship. As a matter of fact, most of the businesses participating in industry-university cooperation in Korea are small and medium enterprises. In other words, although commercialization technologies and the market are secured, they need the resources of universities in terms of research capabilities and manpower. Given this, Korean industry-university cooperation is greatly affected by the government's policies that provide financial support via. a variety of programs.

This research is to verify the effectiveness of the policies for industry-academic cooperation through LINC (Leaders in University-Industry Cooperation), a project that supports cooperation between academia and businesses in the context of resource dependence theory. The relationship between various actors and the performance of industry-university cooperation is analyzed based on the indicator of the LINC and the achievements over last 4 years. Furthermore, implications for future policies will be suggested.

\section{Literature review}

Resource-dependence theory: University-industrial cooperation can be interpreted in light of the resource dependence theory. The theory of resource dependence is one of the organizational theories that emphasizes adaptability to the environment, assuming that the organization is open to the environment. In resource dependency theory, an organization basically assumes that it cannot be self-sufficient by itself with complete resources and is constantly supplied with resources from outside organizations against constantly changing environments (Aldrich and Pfeffer, 1976). Thus, it focuses on how organizations acquire resources

Corresponding Author: Gyeong-Min Nam, Industry Cooperation Team, National Research Foundation of Korea, Busan, South Korea 

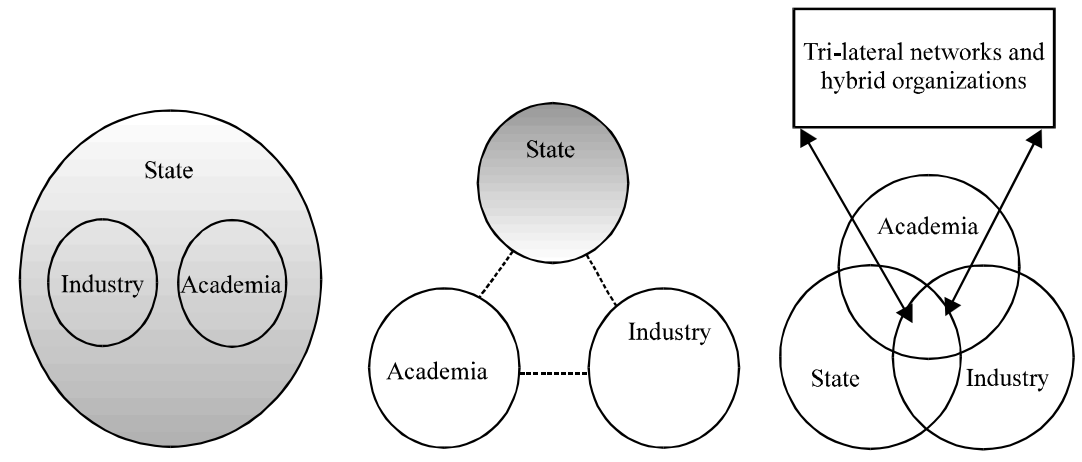

Fig. 1: Triple helix configurations (Etzkowitz and Leydesdorff, 2000)

such as resources, manpower and technical knowledge that affect the survival of an organization in a constrained situation.

According to this theory, it suggests two conditions that determine the degree of external dependency of the organization as follows. In other words, the dependence of an organization on an external actor or organization is inversely proportional to the degree to which the organization places an emphasis on external mediated goals and is inversely proportional to the extent to which that goal can be achieved outside of specific relationships (Pfeffer and Salancik, 2003). In other words, when an organization $\mathrm{A}$ is in a position to control the use and allocation of resources that are essential for the survival of the organization $\mathrm{B}$ and the organization $\mathrm{B}$ does not have a source to obtain the resource other than the organization $\mathrm{A}$, the reliance on in other words, according to the theory of resource dependence, the determinants of dependency between two organizations can be seen as importance of resources, control and discretion of resources and substitutability of resources (Pfeffer and Salancik, 2003).

Resource dependence theory sees dependency as a power relation. In the above example, when the organization $\mathrm{B}$ depends on the organization $\mathrm{A}$, the organization $\mathrm{A}$ has authority over the organization B. If the two parties are in an interdependent relationship, the lower the dependence on the other in terms of the importance of the resource, the dominance and the discretion, In this form of power relations, those with power can make those who depend on them behave if they were equal (Pfeffer and Salancik, 2003). In other words, the result of the power relationship leads to the so-called "relationship between power and no power" which draws the involuntary adaptation of the organization with high dependency.

In the context of industry-academia cooperation, it means that industries lacking important resources such as R\&D capability, financial support, professional manpower and equipment can depend on universities that can supply the resources to achieve their corporate goals. It also explains the reason why universities and companies have to participate in industry-academia cooperation activities in order to receive financial support of 5 billion won per year.

Triple helix model: The triple helix model provides the idea that the hybridization of innovative elements from university, industry and government create innovation in production, transfer and application of knowledge. (Etzkowitz and Leydesdorff, 2000) It can be divided into a statist model, a Laissez-Faire Model and a normative model depending on the relationship between the three spheres (Fig. 1).

In the triple helix model, it is explained that the spiral is formed through three development stages according to the interaction type between university, company and government. The first is the stage where internal transformation is generated according to each environmental change. As described above, as we enter the knowledge-based society, knowledge producers, including universities, redefine or expand the function of the institution itself in order to be competitive (Etzkowitz, 2003). This transformation takes place not only through internal change but also through collaboration with external organizations. For example, in the case of universities, based on government policies and resources, the university will expand its outreach through the establishment and operation of industry-academia cooperation groups, reorganization of bachelor's degree, technology transfer and spin-off. Also, through joint research and development with government and universities, the government expands the scope of activity through financial support. In the second stage, one spiral affects the other spiral, causing a change. For example, if the government establishes laws and institutions to encourage university-industry cooperation, universities and businesses will be affected. The final step is the creation of a new three-way network and organization through the interaction of the three spirals. 
This starts with each party creating a plan to produce and share ideas and achieve them in order to create innovation. As a result of these activities, new organizations such as technology transfer centers and research centers are created and each subject interacts and exchanges functions and influences (Etzkowitz, 1983; Kyung-Hee et al., 2017; Lee and Lee, 2016; Lee and Ju, 2015; Lee and Yoel, 2015)

The triple helix, thus, formed can be divided into Nationalism Model, free-space model and normative model according to the relationship between the subjects. First, the statistic model plays the role of leading the industry-university cooperation through the government's policy and financial support and coordinating the academic and industrial relations. The Laissez-Faire Model on the other hand is a form in which each subject has a clear boundary and works in each area and establishes a loose connection. In other words, the government has limited interaction with regulatory activities through the system, education and research at universities and production and economic activities. Most countries are trying to make the transition to the third model which can be described as nationalism or liberalism but as each has its limitations. The third model, the normative model is a new and innovative knowledge production where the intersection of regions overlaps with that of universities, governments and corporations sharing their domains in a horizontal relationship.

Since, government introduced the concept of university-industry and supported it by policies from the 1960 's, Korea has maintained a framework close to a Statist Model. Thus, this study explores how the government policy influences the collaboration and university and business interact based on the triple helix model.

\section{MATERIALS AND METHODS}

Definition of university-industry cooperation: There is no agreed definition of industry-academia cooperation and it is conceptualized variously according to research subjects and laws. The Ministry of Education and the Ministry of Industry which are major departments of the financial support program for universities, define it as cooperation among national and local governments, research institutes and industries in the "Promotion of Industrial Education and Scientific Research Cooperation Act.", according to the law, it contains activities such as joint use of tangible and intangible resources, conducting $\mathrm{R} \& \mathrm{D}$, nurturing next generation, commercialization to create knowledge and technology and nurture human resources reflecting the demand of future industry. In addition, industry-university cooperation is stipulated in various laws and policies as shown in Table 1.

\section{Data collection and research methods}

Research model: The purpose of this study is to figure out how the university's capability of university-industry cooperation affects actual performance using LINC data. To identify the critical factors, we conducted factor analysis of LINC's core performance indicators (21) and fundamental indexes (3). As a result, the independent variables representing the capability, were set in three groups; scale of participating group, entrepreneurship cultivation, Industry liaison programs. In the same way, the university-industry performance was categorized into three groups; technology transfer and commercialization, specialized field performance, joint R\&D (Fig. 2). In this study, assumptions are made and verified as follows:

$\mathbf{H}_{1}$ : The size of participating business groups (number of students and full-time faculty members), the capacity of start-up support from university authority(number of courses, financial support for start-ups, number of professors experienced in industry) and industry liaison programs (placement participation ratio, capstone design participation, number of associated company) have a positive effect on the performance of technological commercialization.

$\mathbf{H}_{2}$ : The size of participating business groups (number of students and full-time faculty members), the capacity of start-up support from university authority (number of courses, financial support for start-ups, number of professors experienced in industry) and industry liaison programs (placement participation ratio, capstone design participation, number of associated company) have a positive effect on the performance in specialized field.

$\mathbf{H}_{3}$ : The size of participating business groups (number of students and full-time faculty members), the capacity of start-up support from university authority (number of courses, financial support for start-ups, number of professors experienced in industry) and industry liaison programs (placement participation ratio, capstone design participation, number of associated company) have a positive effect on the performance of technological commercialization.

Approach and method: This study, in order to approach the topic, has adopted quantitative analysis based on actual achievement data. By verifying a relationship between factors such as capability, manpower and policy, it would help the subjects of university-industry 
Table 1: Definition of university-industry cooperation

Law and regulation

University-Industry Cooperation

Initiative (2002)

The Presidential Committee on

Balanced National Development (2004)

Vocational Education and Training Promotion Act (2011)

Promotion of Industrial Education and Scientific Research Cooperation Act (2014)
Definition

Cooperation of industrial, university, and research institutes is the phenomenon of interactions between related businesses such as research and technology development, workforce training, and technology transfer Academy-industrial cooperation is a division of the traditional government-led supply-centered from the providercentered to the consumer-focused enterprise and surrounding it (universities, businesses, government, economic groups) collaborative working groups, and comprehensive educational units for industrial purposes in the scope of support

"Cooperation of industrial relations" means the activity of vocational training institutions and businesses (including industrial organizations and research institutes) working together on the development of industrial workforce and the development of industrial technologies, respectively:

A study on joint use and cooperative research of human resources, facilities and professional education

Installation of department or vocational training courses under special agreement

Consignment of vocational education and training

University-academia cooperation means the activities of the following items, which are carried out in cooperation between the govemment, local govemments, research institutes and businesses.

Promotion of talents according to the needs of industry and future industrial development

Research, development, and commercialization for the creation and diffusion of new knowledge and technology

Technology transfer and consulting to industry

Joint utilization of employees, facilities, equipment, research and development information

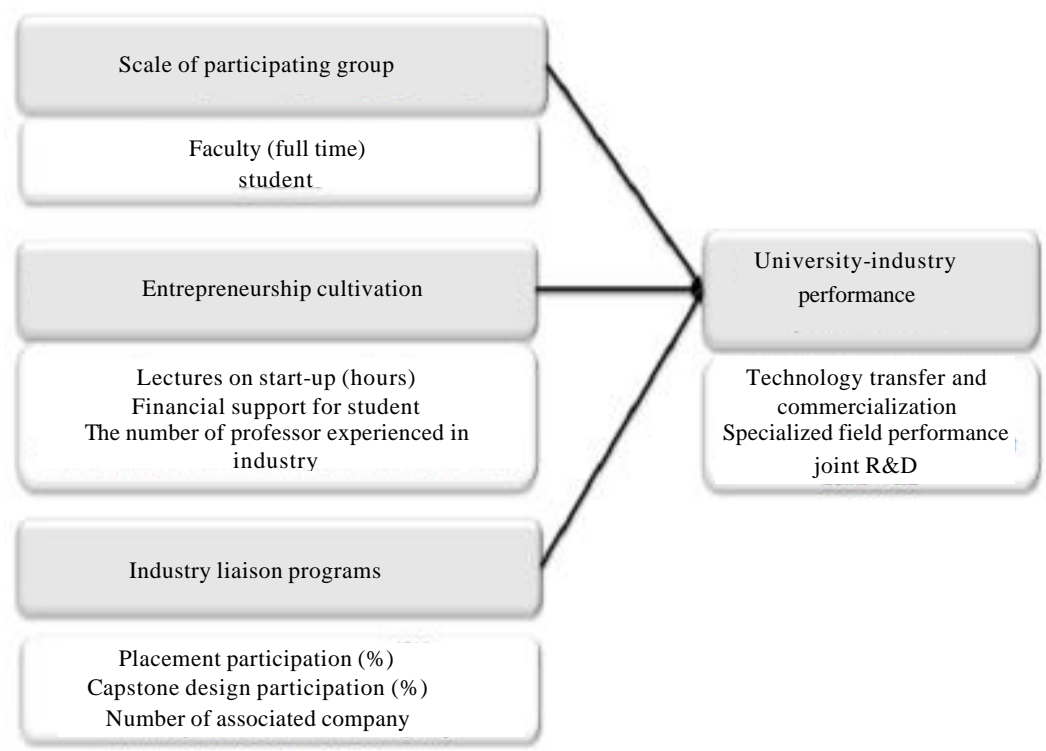

Fig. 2: Research model

collaboration to improve their performances. Therefore, we hereby find out what factors has influences on university-industry cooperation via regression analysis method.

The analysis method used in this study is as follows. First, we tested the independence and normality of variables to determine whether basic assumptions are satisfied before regression analysis. In order to check whether the variables are regularly distributed, skewness and kurtosis were measured. In addition, to meet the independence between variables, we used a correlation analysis to remove the multicollinearity between independent variables. Furthermore, the independence between variables was confirmed by Variance Inflation Factor (VIF) while regression analysis. The independence between the error terms was tested using the Durbin-Watson values. Next, we conducted multiple regression to analyze the relations between independent variables and dependent variables. Data analysis was done using Windows SPSS 22.0 program

\section{RESULTS AND DISCUSSION}

The descriptive statistics of main variables: The characteristics of the data used in this study are as follows. The Leaders in Industry-university Cooperation (LINC) program started to encourage universities to nurture talents and boost technological innovation by establishing leading models of industry-university collaboration that meet the demand of local industry. The project had supported 68 universities from 2012-2016. 


\begin{tabular}{|c|c|c|c|c|c|c|c|c|}
\hline $\mathrm{FY}$ & \multicolumn{2}{|c|}{2012} & 2013 & \multicolumn{2}{|r|}{2014} & \multicolumn{2}{|r|}{2015} & 2016 \\
\hline No. of universities & \multirow{2}{*}{\multicolumn{2}{|c|}{$\begin{array}{l}51 \\
165,000\end{array}$}} & 51 & \multirow{2}{*}{\multicolumn{2}{|c|}{$\begin{array}{l}55 \\
231,800\end{array}$}} & \multirow{2}{*}{\multicolumn{2}{|c|}{$\begin{array}{l}57 \\
218,109\end{array}$}} & \multirow{2}{*}{$\begin{array}{l}57 \\
217,239\end{array}$} \\
\hline Annual budget (IK USD) & & & 241,750 & & & & & \\
\hline & \multicolumn{2}{|c|}{ Tech transfer } & \multicolumn{3}{|l|}{ Special field } & \multicolumn{2}{|c|}{ Joint R\&D } & \multirow[b]{2}{*}{ Employment (\%) } \\
\hline D.V/I.V & No. & Revenue & Manpower & Tech com & ercialization & Funding & No. of project & \\
\hline \multicolumn{9}{|l|}{ No. of group } \\
\hline Student & & $(-)$ & $(+)$ & & & & & \\
\hline Faculty & & $(+)$ & & $(+)$ & & $(+)$ & & $(+)$ \\
\hline Course (h) & & $(-)$ & & & & $(-)$ & & \\
\hline \multicolumn{9}{|l|}{ Entreprenurship cultivation } \\
\hline Funding & & $(+)$ & & $(+)$ & & & & \\
\hline UIC-oriented faculty & & & $(+)$ & $(+)$ & & $(-)$ & & $(-)$ \\
\hline Placement (\%) & & $(-)$ & $(+)$ & & & $(-)$ & & \\
\hline \multicolumn{9}{|l|}{ Industry liaison programs } \\
\hline Capstone design (\%) & $(+)$ & $(+)$ & & & & & $(+)$ & $(+)$ \\
\hline No. of associated company & $(+)$ & $(+)$ & & & & $(+)$ & & $(+)$ \\
\hline
\end{tabular}

In order to identify how university capacity of university-industry cooperation affects its performance, we conducted multiple regression analysis. Dependent and independent variables were determined through factor analysis and literature review. The former are the size of participants, entrepreneurship cultivation and industry cooperation. The latter are identified as achievement in technology transfer, specialized field and industry cooperation. The results are as follows:

First, the size of participating group shows positive relationship with the specialized field performance and joint R\&D but does not have a consistent effect on technology transfer and commercialization. Specifically, the number of participating faculties has a positive relationship with all three dependent variables which indicates that the greater the number of faculty members dedicated to industry-university cooperation, the higher the performance of industry-university cooperation can be. On the other hand, it seems that the number of participating student only contributes to the nurturing talents in specialized fields. Therefore, it can be interpreted that the size of the full-time faculty devoted to the university-industry collaboration has a significant effect on the university-industry cooperation performance rather than the size of the participating students (Table 2 and 3 ).

Second, entrepreneurship cultivation including lectures and hiring professors is contributes to increase performance in specialized field, there was no specific relation with technology transfer and commercialization. Concerning industry joint R\&D performances, it shows negative relationship. This is because financial supports for the student start-up or the recruitment of professors who have experience in businesses have a significant effect on the training of the talents that meet the demand from industry as they aim. However, it seems that these activities do not lead to follow ups such as the technology transfer or joint R\&D with industry. In particular, professors with experience in industries were expected to be mediators between universities and industry but in practice, they have a negative relationship with employment rate and the number of collaborative R\&D. It can be interpreted that they do not act as a bridge between academia and business. Thus, there needs to find out the cause from both parties and reform related institutions. Also, start-up courses do not have a significant effect on the most performance indexes and even show a negative effect on technology transfer and collaborative research. It indicates that the curriculum only provides a theoretical knowledge such as history, marketing and organizational theories and it does not work in practice. Therefore, it is necessary to analyze trends and needs of market first, then improve the curriculums in the way to help students develop an idea to an actual goods or services and learn how to operate enterprises.

Third with industry liaison programs, the result shows that they have a positive relationship with the increase in performance. It can be interpreted that the capstone design programs run on the demands of the industry as it aims and furthermore, it leads to employment of students with the assistance of associate companies. In other words, students can improve their own ability and insight while solving problems in the capstone design class and then associate companies can develop the idea in the way of technology transfer or simply hire the talents. However, in the case of on-the-job training, it does not have a significant effect on strengthening cooperation with industry against expectation. It implies that students do irrelevant works at the placement or there was miss-match between university 
and company. Therefore, the government and university need to labor demand survey and reform the related policies upon the result.

\section{CONCLUSION}

The implications of this study are as follows. This study is significant in verifying the factors influencing the achievement of university-industry cooperation based on the empirical data of government financial support projects. In the previous research, the results of the industry-university cooperation policy were analyzed through qualitative methods such as questionnaire survey and interviews. Therefore, in this study, quantitative analysis of industry-university cooperation performances based on empirical data and core competence indicators of LINC suggests implication for the effectiveness of the previous policy and future direction.

Financial support for start-ups, capstone design curriculum and associated company system has a positive effect on performance improvement which can be set as an encouraging indicator for follow-up program. However, it seems that professors hired to bridge industry and academia, on-the-job training courses and start-up lectures which showed negative (-) effects on some industry-university cooperation performance variables, do not reflect current industry demand. In particular, since, it does not have a significant effect on the joint R\&D promotion with the industry which is the main goal of the LINC project and the student employment. Therefore, it is needed to improve the related index in the next program.

\section{LIMITATIONS}

In this study, we analyzed the factors affecting the achievement of university-industry cooperation by using indicators of the LINC project and verified the effectiveness of the project. However, it has the following limitations.

First, this study used the data provided by the funding agency, National Research Foundation of Korea, thus data's reliability and validity is verified. Nevertheless, the number of LINC universities is limited and it is difficult to fully explain the factors that affect the performance of industry-university cooperation through the analysis results.

\section{RECOMMENDATIONS}

In order to complement this, we can expand the research on LINC non-participating universities and analyze the factors influencing the achievement of university-industry cooperation based on the performance indicators presented in the government financial support project. Second, in spite of the data's feature, there was a lack of correlation verification between time series data. In this study, due to the lack of relevant data, the trends reflecting various characteristics of each university such as university size and specialization field could not be tested in advance and each data was treated as segmented. It is needed to be considered in the future complementary studies.

\section{ACKNOWLEDGEMENTS}

It is a great pleasure to present this study and we would like to express our gratitude for reviewers and Prof. Choi of Korea University who shared their time and expertise. The Researcher (Gyeong-Min, Nam) resides in 60, Daedeok-daero 175 Beon-gil, Seo-gu, Daejeon, Republic of Korea. The researcher (Dae-Geon Kim) resides in 120, Naengjeong-ro, Sasang-gu, Busan, Republic of Korea.

\section{REFERENCES}

Aldrich, H.E. and P. Jeffrey, 1976. Environments of organizations. Annu. Rev. Sociology, 2: 79-105.

Etzkowitz, H. and L. Leydesdorff, 2000. The dynamics of innovation: From national systems and Mode 2 to a Triple Helix of university-industry-government relations. Res. Policy, 29: 109-123.

Etzkowitz, H., 1983. Entrepreneurial scientists and entrepreneurial universities in American academic science. Minerva, 21: 198-233.

Etzkowitz, H., 2003. Triple Helix: A Manifesto for Innovation, Incubation and Growth. SNS Press, Stockholm, Sweden,

Kyung-Hee, C., L. Nam-Su and P. Soon-Gil, 2017. The effects of the resilience of university student on selfdirected learning ability and happiness index. Asia Pac. J. Educ. Manage. Res., 2: 83-88.

Lee, H.S. and L.S. Yoel, 2015. Analysis of various influences and factors on academic persistence of cyber university students. Intl. J. U. E. Serv. Sci. Technol., 8: 211-222.

Lee, S.Y. and H.S. Lee, 2016. Analysis of the effect of university specialization of academic fields on university education outcomes. Intl. J. U. E. Serv. Sci. Technol., 9: 365-376.

Lee, S.Y. and H.Y. Ju, 2015. Effects of participating in mentoring activities for self leadership and super leadership development in university students. Intl. J. U. E. Serv. Sci. Technol., 8: 151-160.

Pfeffer, J. and G.R. Salancik, 2003. The External Control of Organizations: A Resource Dependence Perspective. Stanford University Press, Palo Alto, California, USA., Pages: 289. 